\title{
Histopathological Evaluation of Endometrium in Perimenopausal Women with Fibroids
}

\author{
${ }^{1}$ Peeyusha W Rajani, ${ }^{2}$ Annie Rajaratnam
}

\begin{abstract}
Background: Steroid hormones causes functional and structural changes in endometrium throughout each menstrual cycle. Uterine leiomyomas being dependent on steroid growth hormones for their growth and maintenance account for more than $75 \%$ of the benign tumors in females of childbearing age group. Formation of fibroids hence is a common response to this pathologic state. The aim of our study was to correlate endometrial histopathology in perimenopausal women with fibroids presenting as abnormal uterine bleeding (AUB-L).
\end{abstract}

Materials and methods: Fifty women of perimenopausal age, presenting with abnormal uterine bleeding, wherein the uterus revealed leiomyoma were studied. Endometrial thickness was measured using vaginal or pelvic ultrasonography. Endometrial biopsy was taken, and the samples were sent for histopathological examination. Ten asymptomatic normal women of similar age group were taken as controls.

Results: Uterine size was nonsignificantly increased in a perimenopausal woman with fibroid. The average size of fibroid was 3.10 to $3.24 \mathrm{~cm}$. Mean endometrial thickness with fibroid was significantly higher as compared to normal females of similar age group.

Conclusion: Presence of fibroid was associated with an increase in endometrial thickness in perimenopausal women, along with a small change in uterine size.

Keywords: Abnormal uterine bleeding, Endometrial thickness, Leiomyoma, Perimenopausal women.

How to cite this article: Rajani PW, Rajaratnam A. Histopathological Evaluation of Endometrium in Perimenopausal Women with Fibroids. J South Asian Feder Menopause Soc 2018;6(2):88-90.

\section{Source of support: Nil}

Conflict of interest: None

Date of received: 10 January 2018

Date of acceptance: 27 January 2018

Date of publication: July 2018

\footnotetext{
${ }^{1}$ Postgraduate Student, ${ }^{2}$ Associate Professor

1,2Department of Obstetrics and Gynaecology, Yenepoya Medical College, Mangaluru, Karnataka, India
}

Corresponding Author: Annie Rajaratnam, Associate Professor, Department of Obstetrics and Gynaecology, Yenepoya Medical College, Mangaluru, Karnataka, India, e-mail: annierajaratnam@yahoo.com

\section{INTRODUCTION}

The absence of menstrual periods for 1 year is termed as menopause. Normally menopause occurs between $45-55$ years of age, with a mean age of 51 years. Perimenopausal bleeding is a clinically significant complaint in general gynecologic practice. Benign genital causes of peri-menopausal bleeding include atrophic vaginitis, endometrial and cervical polyps, endometrial hyperplasia. ${ }^{1,2}$ The endometrium shows structural changes throughout the menstrual cycle in response to steroid hormones. During the follicular phase, estrogen levels steadily rise leading to blood flow to stop, and gradually the endometrial thickens. ${ }^{3}$ Once ovulation occurs, corpus luteum starts producing progesterone which causes uterine lining changes, making it suitable for implantation. If implantation does not occur over the period of the next two weeks, the corpus luteum involutes, leading to decreased production of both progesterone and estrogen. This sudden decrease in hormonal levels leads to shedding of endometrium lining known as menstruation. ${ }^{4}$

The uterus is subject to a variety of disorders, the most common result of which result from smooth muscle tumors. Leiomyomata (uterine fibroids) are the most common tumors of the female pelvis. The myometrium of leiomyomas expresses higher levels of estrogen receptors a fact related to pathogenesis. ${ }^{5}$ Many other factors have been considered on a theoretical basis, one of them being heredity. Epidemiological and clinical surveys in the United States have shown that the incidence of fibroids was more common in blacks than in whites. This finding can be related to a higher incidence of pelvic infections leading to myometrial irritation caused by these infections. Gene encoding has been postulated as another risk for fibroid development, particularly deletions of the chromosome, which are found in up to $50 \%$ of fibroid specimens. ${ }^{6}$

Studies have indicated that fibroids are monoclonal tumors which evolve from a single myocyte, but the enticing event for neoplastic transformation is currently unknown. Fibroids are classified as true neoplasms rather than hyperplastic proliferation. High testosterone with high estradiol levels is often associated with an increased risk of incident fibroids in perimenopausal women. ${ }^{7}$

Since uterine leiomyomas are more common during childbearing age groups, it can be related to their 
steroid dependence for growth. Rapid growth and hemorrhagic degeneration of fibroids during pregnancy, clomiphene and progesterone treatment, further indicates the dependence of fibroids on female sex hormones for their growth. ${ }^{6,7}$ Differentiation of myofilaments of smooth muscles is triggered by estrogen and progesterone. ${ }^{7}$

\section{MATERIALS AND METHODS}

The study was conducted at a tertiary care center at Mangaluru from May 2018 to October 2018. A total of 50 cases of perimenopausal women with leiomyoma presenting as AUB were studied. A detailed history was obtained from patients which included age, clinical presentation, parity, and menstrual phase. All patients diagnosed with fibroids were sent for ultrasonography (USG), where uterus size, fibroid size, and endometrium thickness was assessed via transvaginal or transpelvic ultrasonography. Endometrial biopsy was taken, and the sample was sent for microscopic examination, to study endometrial pathology. The uterine size was assessed in a longitudinal plane, while endometrial thickness was measured at the thickest point between two basal layers on the anterior and posterior walls. Ten normal females of perimenopausal age group with no complaints with normal uterine size and endometrial thickness were taken as controls.

\section{RESULTS}

Fifty females of perimenopausal age group were included in the study. Ten females of similar age group with no apparent complaints and no evidence of fibroids on USG and endometrial thickness of $<6 \mathrm{~mm}$ were taken as controls.

Table 1 shows patients with fibroids had non significantly $(p<0.05)$ larger uterine size as compared to

Table 1: Comparison of uterine size in patients with fibroids and controls

\begin{tabular}{llll}
\hline & $\begin{array}{l}\text { Mean } \\
\text { age in } \\
\text { years }\end{array}$ & $\begin{array}{l}\text { Mean uterine size } \\
\text { in cms }\end{array}$ & $\begin{array}{l}\text { Mean fibroid } \\
\text { size in cms }\end{array}$ \\
\hline Control & $48.23 \pm$ & $8.25 \times 3.53 \times 4.27$ & - \\
$(\mathrm{N}=10)$ & 3.34 & $\pm 1.16 \times 0.92 \times 1.01$ & \\
Patients & $49.17 \pm$ & $8.76 \times 4.55 \times 6.48$ & $3.24 \times 3.10$ \\
$(\mathrm{~N}=50)$ & 4.68 & $\pm 2.94 \times 1.20 \times 2.39$ & $\pm 0.60 \times 0.85$ \\
\hline
\end{tabular}

Table 3: Incidence of histopathological pattern of endometrium

\begin{tabular}{ll}
\hline Endometrial pattern & Percentage \\
\hline Proliferative & 68 \\
Secretory & 14 \\
Hyperplasia & 4 \\
Cystic glandular hypertrophy & 2 \\
Atrophic & 6 \\
Unknown & 6 \\
\hline
\end{tabular}

controls of similar age groups. Mean fibroid size seen in patients were $3.24 \times 3.10 \pm 0.60 \times 0.85 \mathrm{~cm}$. Table 2 shows patients with fibroids had significantly ( $p$ value 0.0487 ) higher endometrial thickness. Histopathological patterns in endometrium are depicted in Table 3 , showing proliferative endometrium in $68 \%$, secretory changes in $14 \%$, endometrial hyperplasia in $4 \%$ cases, cystic glandular hypertrophy in $2 \%$, and atrophic endometrium in $6 \%$. In the patient who underwent hysterectomy, cystic ovaries were seen in $8 \%$, adenomyosis in $12 \%$, chronic cervicitis in $67 \%$, endometriosis in $2 \%$, and PID in $4 \%$ of the cases as outlined in Table 4.

\section{DISCUSSION}

Any menstrual cycle lasting for more than 8 days is termed as abnormal uterine bleeding, and if occurs in the peri-menopausal age group, it accounts for medical and surgical intervention. ${ }^{8}$ Our study showed that the presence of fibroid was associated with an increase in uterine size in perimenopausal women as compared to normal controls. Subserosal fibroids due to distortion of pelvic anatomy impair the fallopian tubes to capture an egg at the time of ovulation, hence further adding to cause of infertility. ${ }^{9}$

De Castro et al. in their study reported that the uterine cavity shape and size can change with the presence of fibroid, leading to an increase in total uterine length, and transverse fundal diameter can vary dramatically. ${ }^{10}$ Cavity length was found to be on the higher side in older and parous women in a study conducted by Somigliana et al. ${ }^{11}$ Mean uterus size of $8.76 \times 4.55 \times 6.45 \mathrm{~cm}$ was observed in our study which was in contrast to the study conducted by Esmaelzadeh et al. ${ }^{12}$

Porozhanova et al. in their study observed that subserosal fibroids do not disturb the uterine cavity significantly and were unable to associate the presence of subserosal fibroids with infertility. The incidence of cesarean deliveries increased with the presence of fibroids of a size larger than $5 \mathrm{~cm} \cdot{ }^{13}$ Endometrial thickness was

Table 2: Comparison of endometrial thickness in patients and controls

\begin{tabular}{llll}
\hline Subjects & $\begin{array}{l}\text { Control } \\
(n=10)\end{array}$ & $\begin{array}{l}\text { Patients } \\
(n=50)\end{array}$ & $p$ value \\
\hline Perimenopausal & $5.25 \pm 0.50$ & $6.00 \pm 1.15$ & 0.0487 \\
\hline
\end{tabular}

Table 4: Histopathological abnormalities in combination with myoma

\begin{tabular}{ll}
\hline Associated pelvic pathology & Percentage \\
\hline Cystic ovary & 8 \\
Chronic cervicitis & 67 \\
Adenomyosis & 12 \\
Endometriosis & 2 \\
Pelvic inflammatory disease & 4 \\
\hline
\end{tabular}


found to be increased in perimenopausal women with the presence of fibroid. Endometrial thickness of $8 \mathrm{~mm}$ is considered to be of optimal sensitivity and specificity by some researchers. ${ }^{14,15}$

Endometrial thickness is often associated with endometrial carcinoma. Presence of uterine fibroids can lead to thickened endometrial thickness as observed by Ozdemir et al. ${ }^{16}$ Studies have shown the mean endometrial thickness of $3.97 \mathrm{~mm}$ in perimenopausal women. Endometrial response to estrogens and it serves as a biomarker of estrogen status in perimenopausal women. ${ }^{5}$ On histological examination, the proliferative type was seen in $68 \%$ cases, which is similar to studies conducted by Udawat (68\%) and Chhabra et al. (40\%) and secretory in $14 \%$ cases. ${ }^{17}$

\section{CONCLUSION}

Presence of fibroid was associated with an increase in endometrial thickness in peri-menopausal women, along with the change in uterine size. The proliferative and hyperplastic endometrium was found to be the most common. Fibroids can be associated with hyperestrogenic states. Further studies are needed on a larger number of cases to strengthen the association of endometrial pathology in perimenopausal AUB (M).

\section{CLINICAL SIGNIFICANCE}

Early diagnosis of premalignant changes in the endometrium.

\section{REFERENCES}

1. Astrup K, Olivarius NF. Frequency of spontaneously occurring postmenopausal bleeding in the general population. Acta Obstet Gynecol Scand 2004;83:203-207.

2. Guruwadayarhalli B, Jones SE, et al. Hysteroscopy in the diagnosis of postmenopausal bleeding. Menopause Int 2007;13:132-134.

3. Dockery P. The fine structure of the mature human endometrium. In: Glasser SR, Aplin JD, Guidice LC, Tabibzadeh
S, editors. The Endometrium. London: Informa Health Care 2002;21-36.

4. Crum CP. Body of uterus and endometrium. In: Kumar V, Abbas AK, Fausto N, editors. Robbins and Cotran Pathologic Basis of Disease. 7th edn. Philadelphia: Saunders, 2004;10891090.

5. Gull B, Karlson B, et al. Factors associated with endometrial thickness and uterine size in random samples of postmenopausal women. Am J Obstet Gynecol 2001;185(2): 386-391

6. Vollenhoven BJ, Lawrence AS, et al. Uterine fibroids: A clinical review. Br J Obstet Gynaecol 1990;97:285-298.

7. Uterus. In: Standring S, editor. Gray's Anatomy, The Anatomical Basis of Clinical Practice. 39th edn. Spain: Elsevier, 2005: 1331-1339.

8. Goldstein SR, Zeltser I, et al. Ultrasonography-based triage for perimenopausal patients with abnormal uterine bleeding. Am J Obstet Gynecol 1997;177(1):102-108.

9. Sulaiman S, Khaund A, et al. Uterine fibroid do size and location determine menstrual blood loss? Eur J Obstet Gynecol Reprod Bio 2004;115(1):85-89.

10. DeCastro A. Assessment of uterine shape and size using Kurz's cavimeter. Adv contracept 1988;4:115-123.

11. Somigliana E, Vercellini $P$, et al. Fibroids and female reproduction: a critical analysis of the evidence. Hum Reprod Update 2007;13(5):465-476.

12. Esmaelzadeh $S$, Rezaei N, et al. Normal uterine size in women of reproductive age in northern Islamic Republic of Iran. East Mediterr Health J 2004;10(3):437-441.

13. Porozhanova V, Porozhanova K. Uterine fibromas and infertility. Akush Ginekol (Sofiia) 2004;43(6):33-38.

14. Dreisler E, Sorensen SS, et al. Value of endometrialthickness measurement for diagnosing focal intrauterine pathology in women without abnormal uterine bleeding. Ultrasound Obstet Gynecol 2009;33(3):344-348.

15. Getpook C, Wattanakumtornkul S. Endometrial thickness screening in premenopausal women with abnormal uterine bleeding. J Obstet Gynaecol Res 2006;32(6):588-592.

16. Ozdemir S, Celik C, et al. Evaluation of endometrial thickness with transvaginal ultrasonography and histopathology in premenopausal women with abnormal vaginal bleeding. Arch Gynecol Obstet 2010;282(4):395-399.

17. Chhabra S, Ohri N. Leiomyoma of uterus-A clinical study. J Obstet Gynaecol Indi. 1993;33:438-439. 